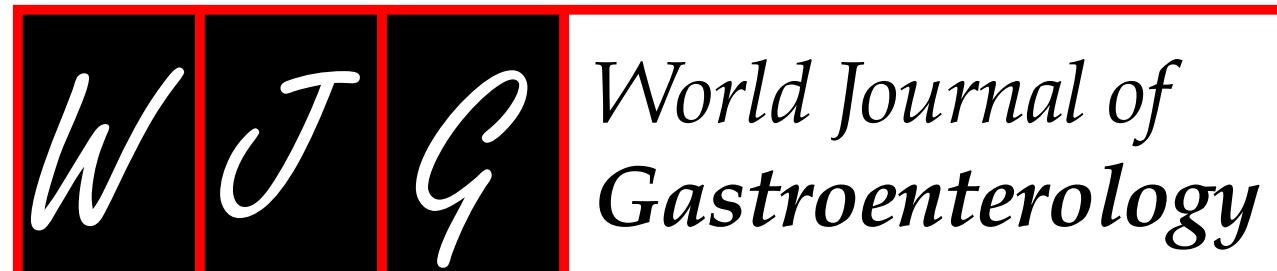

Submit a Manuscript: http:/ / www.f6publishing.com

World J Gastroenterol 2017 June 28; 23(24): 4399-4406

DOI: 10.3748/wjg.v23.i24.4399

ISSN 1007-9327 (print) ISSN 2219-2840 (online)

ORIGINAL ARTICLE

Retrospective Cohort Study

\title{
Para-aortic node involvement is not an independent predictor of survival after resection for pancreatic cancer
}

\author{
Cosimo Sperti, Mario Gruppo, Stella Blandamura, Michele Valmasoni, Gioia Pozza, Nicola Passuello, Valentina \\ Beltrame, Lucia Moletta
}

Cosimo Sperti, Mario Gruppo, Michele Valmasoni, Gioia Pozza, Nicola Passuello, Valentina Beltrame, Lucia Moletta, Departments of Surgery, Oncology and Gastroenterology, $3^{\text {rd }}$ Surgical Clinic, University of Padua, 35128 Padua, Italy

Stella Blandamura, Departments of Medicine, Section of Pathology, University of Padua, 35128 Padua, Italy

Author contributions: Sperti C and Beltrame V conceived the article and drafted the manuscript; Pozza G, Passuello N and Moletta L made Literature revision; Gruppo M and Valmasoni $\mathrm{M}$ made statistical analysis; Blandamura $\mathrm{S}$ made pathological examinations; Sperti C, Valmasoni M, Pozza G, Passuello N, Beltrame V and Moletta L contributed to treatment and follow-up of patients.

Institutional review board statement: The study was reviewed and approved for publication by our Institutional Reviewer.

Informed consent statement: All study participants provided informed written consent prior to study enrollment.

Conflict-of-interest statement: None to declare.

Data sharing statement: The original anonymous dataset is available on request from the corresponding Author at csperti@, libero.it.

Open-Access: This article is an open-access article which was selected by an in-house editor and fully peer-reviewed by external reviewers. It is distributed in accordance with the Creative Commons Attribution Non Commercial (CC BY-NC 4.0) license, which permits others to distribute, remix, adapt, build upon this work non-commercially, and license their derivative works on different terms, provided the original work is properly cited and the use is non-commercial. See: http://creativecommons.org/ licenses/by-nc/4.0/

Manuscript source: Invited manuscript

Correspondence to: Cosimo Sperti, MD, Department of Surgery, Oncology and Gastroenterology, $3^{\text {rd }}$ Surgical Clinic,
University of Padua, Via Giustiniani 2, 35128 Padova,

Italy. csperti@libero.it

Telephone: +39-04-98218845

Fax: +39-04-98218821

Received: January 19, 2017

Peer-review started: January 21, 2017

First decision: February 9, 2017

Revised: February 21, 2017

Accepted: May 19, 2017

Article in press: May 19, 2017

Published online: June 28, 2017

\section{Abstract}

AIM

To analyze the importance of para-aortic node status in a series of patients who underwent pancreaticoduodenectomy (PD) in a single Institution.

\section{METHODS}

Between January 2000 and December 2012, 151 patients underwent PD with para-aortic node dissection for pancreatic adenocarcinoma in our Institution. Patients were divided into two groups: patients with negative PALNs (PALNs-), and patients with metastatic PALNs (PALNs+). Pathologic factors, including stage, nodal status, number of positive nodes and lymph node ratio, invasion of para-aortic nodes, tumor's grading, and radicality of resection were studied by univariate and multivariate analysis. Survival curves were constructed with Kaplan-Meier method and compared with Log-rank test: significance was considered as $P<0.05$.

\section{RESULTS}

A total of 107 patients (74\%) had nodal metastases. Median number of pathologically assessed lymph nodes was 26 (range 14-63). Twenty-five patients (16.5\%) 
had para-aortic lymph node involvement. Thirty-three patients $(23 \%)$ underwent R1 pancreatic resection. Onehundred forty-one patients recurred and died for tumor recurrence, one is alive with recurrence, and 9 are alive and free of disease. Overall survival was significantly influenced by grading $(P=0.0001)$, radicality of resection $(P=0.001)$, stage $(P=0.03)$, lymph node status $(P=0.04)$, para-aortic nodes metastases $(P=$ $0.02)$. Multivariate analysis showed that grading was an independent prognostic factor for overall survival $(P$ $=0.0001)$, while grading $(P=0.0001)$ and radicality of resection $(P=0.01)$ were prognostic parameters for disease-free survival. Number of metastatic nodes, node ratio, and para-aortic nodes involvement were not independent predictors of disease-free and overall survival.

\section{CONCLUSION}

In this experience, lymph node status and para-aortic node metastases were associated with poor survival at univariate analysis, but they were not independent prognostic factors.

Key words: Lymphadenectomy; Pancreas; Pancreatic cancer; Pancreatectomy; Lymph node metastasis; Paraaortic nodes; Survival

(c) The Author(s) 2017. Published by Baishideng Publishing Group Inc. All rights reserved.

Core tip: Para-aortic node involvement by pancreatic cancer is traditionally considered as an advanced disease with poor prognosis. We retrospectively examined our experience of 151 patients with pancreatic cancer who underwent resection and para-aortic lymph nodes sampling. Disease-free and overall survival were worse in patients with para-aortic nodes metastases, but multivariate analysis showed that para-aortic node involvement is not an independent prognostic factor after resection of pancreatic cancer. So, the decision to make pancreatic resection should not be based on the paraaortic node status only.

Sperti C, Gruppo M, Blandamura S, Valmasoni M, Pozza G, Passuello N, Beltrame V, Moletta L. Para-aortic node involvement is not an independent predictor of survival after resection for pancreatic cancer. World J Gastroenterol 2017; 23(24): 4399-4406 Available from: URL: http://www.wjgnet.com/1007-9327/full/v23/ i24/4399.htm DOI: http://dx.doi.org/10.3748/wjg.v23.i24.4399

\section{INTRODUCTION}

Pancreatic cancer remains a very aggressive disease with an overall 5 -year survival of only $5 \%{ }^{[1]}$. Surgical resection followed by adjuvant therapy continues to be the treatment of choice for localized, resectable tumors. Lymph nodes status is traditionally one of the most important prognostic factor for patients who underwent resection for pancreatic cancer ${ }^{[2]}$, but the extent of lymphadenectomy in pancreatic cancer surgery is still debated $^{[3,4]}$. Moreover, the total number of removed nodes and lymph node ratio were recently reported as important indicators of prognosis after surgery ${ }^{[5]}$. Para-aortic nodes involvement (PALNs) is generally considered as metastatic disease, and resection is not recommended $^{[6,7]}$. However, some Author reported survival benefit after surgery even when para-aortic nodes were involved by the tumors; so, the real impact of PALNs involvement in pancreatic cancer patients is still controversial ${ }^{[8]}$. Aim of this study was to evaluate early and late outcome of pancreatic cancer patients who underwent pancreatectomy with sampling of paraaortic nodes, No. 16b1 according to the Japan Pancreas Society classification ${ }^{[9]}$.

\section{MATERIALS AND METHODS}

Data were obtained from a retrospective analysis of a prospective data base of patients who underwent pancreaticoduodenectomy (PD) or total pancreatectomy with PALNs sampling between January 2000 to December 2012 in our Department. During the study period, 340 patients underwent PD for pancreatic neoplasms: after excluding IPMNs, endocrine tumors, cystic neoplasms, pancreatic metastasis, duodenal, ampullary, and bile duct cancers, 176 patients underwent PD for ductal adenocarcinoma of the pancreas. Of these, twenty-five patients who underwent resection after performing chemotherapy or chemoradiation for locally advanced pancreatic cancer in outside setting, were excluded from the study. Finally, 151 patients with pancreatic carcinoma were enrolled in this analysis. They were divided into two groups: patients with negative PALNs (PALNs-), and patients with metastatic PALNs (PALNs+). The two groups were compared in term of demographic features, comorbidities, surgical procedures, perioperative findings, tumor pathological characteristics, perioperative outcomes, disease-free and overall survival. All patients underwent standardized preoperative assessment: routine blood tests and tumor markers CEA and CA19-9 determination, abdominal ultrasound (US), computed assisted tomography (CT) scan, and when needed, Magnetic Resonance Imaging or positron emission tomography (PET). CT with angiographic reconstruction was the preferred imaging for tumor's staging. All surgical procedures were performed by the same surgical team. Limited involvement of superior mesenteric-portal axis (less than $2 \mathrm{~cm}$ ), in absence of extrapancreatic disease and involvement of superior mesenteric artery and/or celiac trunk, was not considered as contraindication to surgery. No patient underwent neoadjuvant therapy. Nomenclature of the Japanese Pancreas Society was selected for nodal stations in pancreatic surgery ${ }^{[9]}$. Resection of the pancreas included pylorus-preserving PD for tumors of the head of the pancreas and total pancreatectomy when resection margin of the pancreas was involved by the 
Table 1 Comparison of clinicopathological characteristics of patients with or without para-aortic nodesinvolvement

\begin{tabular}{|c|c|c|c|c|}
\hline & $\begin{array}{c}\text { Total } \\
(n=151)\end{array}$ & $\begin{array}{c}\text { PALNs- } \\
(n=126)\end{array}$ & $\begin{array}{c}\text { PALNs+ } \\
(n=25)\end{array}$ & $P$ value \\
\hline Mean/median age & $65 / 67$ & $65 / 66$ & $65 / 68$ & \\
\hline \multicolumn{5}{|l|}{ Sex } \\
\hline $\mathrm{F}$ & 75 & 59 & 16 & 0.13 \\
\hline $\mathrm{M}$ & 76 & 67 & 9 & \\
\hline \multicolumn{5}{|l|}{ Type of surgery } \\
\hline PD & 146 & 122 & 24 & 1.00 \\
\hline TP & 5 & 4 & 1 & \\
\hline Vascular resection & 29 & 21 & 8 & 0.09 \\
\hline \multicolumn{5}{|l|}{ Tumor (T) } \\
\hline 1 & 6 & 6 & 0 & 0.50 \\
\hline 2 & 17 & 14 & 3 & 1.00 \\
\hline 3 & 107 & 90 & 17 & 0.80 \\
\hline 4 & 21 & 16 & 5 & 0.50 \\
\hline \multicolumn{5}{|l|}{ Nodes status $(\mathrm{N})$} \\
\hline Neg & 39 & 39 & 0 & 0.003 \\
\hline Pos & 112 & 87 & 25 & \\
\hline \multicolumn{5}{|l|}{ Grading (G) } \\
\hline 1 & 15 & 11 & 4 & 0.20 \\
\hline 2 & 89 & 77 & 12 & 0.20 \\
\hline 3 & 47 & 38 & 9 & 0.60 \\
\hline \multicolumn{5}{|l|}{ Radicality } \\
\hline Yes & 113 & 100 & 13 & 0.009 \\
\hline No & 38 & 26 & 12 & \\
\hline \multicolumn{5}{|l|}{ Adjuvant therapy } \\
\hline Yes & 143 & 120 & 23 & 0.74 \\
\hline No & 8 & 6 & 0 & \\
\hline
\end{tabular}

PALNs: Para-aortic lymph nodes; PD: Pancreaticoduodenectomy; TP: Total pancreatectomy; Grading 1, 2, 3: Well, moderate, poor differentiated cancer.

tumor, or when pancreatic anastomosis was judged at high risk of leakage. All patients underwent standard lymph node dissection $(5,6,8 a, 12 b 1,12 b 2,12 c, 13 a$, $13 \mathrm{~b}, 14 \mathrm{a}$ and 14b right lateral side, 17a, 17b) and paraaortic sampling. Para-aortic nodes were excised by harvesting the lymphocellular aortocaval tissue located below the left renal vein until the origin of inferior mesenteric artery (station $16 \mathrm{~b} 1)^{[9]}$. Curative resection was defined as tumor's resection with pathologically confirmed negative margins. R1 resection was defined as the presence of tumor $\leqslant 1 \mathrm{~mm}$ from the margin, according to Leeds criteria ${ }^{[10]}$. Tumor was staged according to UICC (TNM) classification ${ }^{[11]}$. Perioperative morbidity and mortality were investigated in both groups: operative mortality was defined as death within $30 \mathrm{~d}$ from operation, or during hospitalization. Pancreatic fistula was defined as the drainage of fluid with an elevated level of amylase, and graded according to the International Study Group of Pancreatic Fistula recommendations $^{[12]}$. Age, stage, lymph-node status, number of positive lymph nodes ( $<3$ or $>3$ ), lymph node ratio (number of metastatic/total number of lymph nodes), para-aortic node status, grading, and radicality of resection were recorded as potentially prognostic factors. Operative morbidity, mortality, disease-free and overall survival were analyzed. All patients underwent regular follow-up that included physical examination, abdominal CT or US, tumor markers determination every 3 mo for the first 2 years, and every $6 \mathrm{mo}$, thereafter. Adjuvant gemcitabine-based chemotherapy was scheduled for all patients whenever applicable.

\section{Statistical analysis}

The $\chi^{2}$ test or Fisher's exact test was used for comparison among the two groups. Survival curves were constructed with the Kaplan-Meier method and compared by the univariate Log-rank test: significance was considered as $P<0.05$. Tumor's stage, grading, lymph node status, number of metastatic lymph nodes, lymph node ratio, para-aortic node involvement and radicality of resection, were considered as prognostic factors. Independent prognostic variables were evaluated with a Cox regression hazard model. Statistical analysis was performed using the SPSS statistical software package (version 18.0; SPSS Inc., Chicago, IL, United States).

\section{RESULTS}

During the study period, 340 patients underwent PD for pancreatic neoplasms: after excluding IPMNs, endocrine tumors, cystic neoplasms, pancreatic metastasis, duodenal, ampullary, and bile duct cancers, 176 patients underwent PD for ductal adenocarcinoma of the pancreas. Of these, twenty-five patients who underwent resection after performing chemotherapy or chemoradiation for locally advanced pancreatic cancer in outside setting, were excluded from the study. Finally, 151 consecutive patients with pancreatic carcinoma. underwent PD with para-aortic node sampling, and were enrolled in this analysis: there were 76 males and 75 females with a mean age of 65.4 years (range 31-85). Their clinical and pathological characteristics are summarized in Table 1 . One hundred and twelve patients (74\%) had lymph node metastasis: median number of pathologically assessed lymph nodes was 26 (range 14-63). Para-aortic nodes metastases were detected in 25 patients (16.5\%): all these patients had positive lymph nodes $(P=0.003)$, and they significantly underwent a lower rate of non-radical resection $(P=$ 0.009). Mean number of dissected para-aortic nodes was 5 (range 1-15). There was no operative mortality in this series, while overall morbidity rate was $41 \%$ : complications rate was not different between PALNs+ and PALNs- patients ( $41 \%$ and $39 \%$, respectively), as well as pancreatic fistula rate $(16 \%$ and $17 \%$, respectively). Reoperation rate was not different in the two groups ( $5 \%$ and $6 \%$, respectively). Ninety-five percent of PALNs- patients and all patients with PALNs+ underwent postoperative Gemcitabine-based adjuvant therapy.

\section{Univariate analysis}

Results of univariate analysis are reported in Tables 2 and 3. Poor tumor differentiation $(P<0.0001)$, lymph node status, high tumor's stage, para-aortic node involve- 


\begin{tabular}{|c|c|c|c|}
\hline & Mean survival time $(\mathrm{mo})(95 \% \mathrm{Cl})$ & Median survival time $(\mathrm{mo})(95 \% \mathrm{Cl})$ & $P$ value \\
\hline \multicolumn{4}{|c|}{ Grading $(G)$} \\
\hline $1-2$ & $39.55(32.36-46.74)$ & $24.00(19.87-28.13)$ & \multirow[t]{2}{*}{$<0.001$} \\
\hline 3 & $16.42(12.86-19.98)$ & $14.00(12.57-15.43)$ & \\
\hline \multicolumn{4}{|l|}{ Radicality } \\
\hline R0 & $35.88(29.46-42.31)$ & $22.00(18.36-25.64)$ & \multirow[t]{2}{*}{0.004} \\
\hline R1 & $19.99(12.62-27.38)$ & $13.00(11.45-14.55)$ & \\
\hline \multicolumn{4}{|l|}{ Stage } \\
\hline I - II & $34.82(28.47-41.18)$ & $21.00(17.79-24.21)$ & \multirow[t]{2}{*}{0.03} \\
\hline III-IV & $23.29(14.70-31.87)$ & $14.00(11.40-16.59)$ & \\
\hline \multicolumn{4}{|c|}{ Lymph nodes status } \\
\hline Neg & $43.29(30.37-56.21)$ & $25.00(17.055-32.95)$ & \multirow[t]{2}{*}{0.04} \\
\hline Pos & $27.27(22.52-32.02)$ & $18.00(14.65-21.35)$ & \\
\hline \multicolumn{4}{|c|}{ Number of positive lymph nodes } \\
\hline$<3$ & $26.62(20.87-32.35)$ & $19.00(13.09-24.90)$ & \multirow[t]{2}{*}{0.74} \\
\hline$>3$ & $28.39(20.04-36.74)$ & $17.00(12.93-21.07)$ & \\
\hline \multicolumn{4}{|c|}{ Lymph node ratio } \\
\hline$\leqslant 0.13$ & $31.31(23.69-38.93)$ & $20.00(15.57-24.43)$ & \multirow[t]{3}{*}{0.28} \\
\hline $0.13-0.2$ & $25.11(13.23-36.99)$ & $14.00(9.87-18.13)$ & \\
\hline$>0.2$ & $23.29(16.98-29.61)$ & $18.00(14.57-21.43)$ & \\
\hline \multicolumn{4}{|c|}{ Para-aortic lymph nodes status } \\
\hline Neg & $42.06(29.22-54.89)$ & $25.00(17.17-32.83)$ & \multirow[t]{2}{*}{0.02} \\
\hline Pos & $27.27(22.54-32.02)$ & $18.00(14.64-21.35)$ & \\
\hline
\end{tabular}

Grading 1-2: Well-moderately differentiated cancer; Grading 3: Poor differentiated cancer.

Table 3 Univariate disease-free survival analysis of prognostic factors for patients with pancreatic cancer

\begin{tabular}{|c|c|c|c|}
\hline & Mean DFI time $(\mathrm{mo})(95 \% \mathrm{Cl})$ & Median DFI time $(\mathrm{mo})(95 \% \mathrm{Cl})$ & $P$ value \\
\hline \multicolumn{4}{|c|}{ Grading (G) } \\
\hline $1-2$ & $32.438(24.808-40.068)$ & $13.000(8.597-17.403)$ & $<0.01$ \\
\hline 3 & $10.438(8.011-12.865)$ & $8.000(7.183-8.817)$ & \\
\hline \multicolumn{4}{|l|}{ Radicality } \\
\hline R0 & $29.886(22.892-36.880)$ & $12.000(9.280-14.720)$ & 0.001 \\
\hline R1 & $12.708(6.744-18.671)$ & $8.000(6.256-9.744)$ & \\
\hline \multicolumn{4}{|l|}{ Staging } \\
\hline I - II & $27.222(20.732-33.711)$ & $12.000(9.814-14.186)$ & 0.126 \\
\hline III-IV & $19.772(9.939-29.604)$ & $8.000(6.976-9.0224)$ & \\
\hline \multicolumn{4}{|c|}{ Lymph nodes status } \\
\hline Neg & $34.386(20.868-47.904)$ & $13.000(9.523-16.477)$ & 0.106 \\
\hline Pos & $21.468(16.504-26.432)$ & $10.000(7.686-12.314)$ & \\
\hline \multicolumn{4}{|c|}{ Number of positive lymph nodes } \\
\hline$<3$ & $30.817(21.628-40.006)$ & $10.000(6.746-13.254)$ & 0.150 \\
\hline$>3$ & $20.326(14.615-26.036)$ & $11.000(8.082-13.918)$ & \\
\hline \multicolumn{4}{|c|}{ lymph node ratio } \\
\hline$\leqslant 0.13$ & $30.576(22.593-38.560)$ & $12.000(9.211-14.789)$ & 0.155 \\
\hline $0.13-0.2$ & $17.500(5.595-29.405)$ & $8.000(6.614-9.366)$ & \\
\hline$>0.2$ & $17.397(11.191-23.603)$ & $13.000(8.840-17.160)$ & \\
\hline \multicolumn{4}{|c|}{ Para-aortic lymph nodes status } \\
\hline Neg & $28.206(21.656-34.756)$ & $12.000(9.808-14.192)$ & 0.005 \\
\hline Pos & $11.957(6.132-17.781)$ & $8.000(6.853-9.147)$ & \\
\hline
\end{tabular}

DFI: Disease-free survival; Grading 1-2: Well-moderately differentiated cancer; Grading 3: Poor differentiated cancer.

ment and margin involvement were associated with poor survival, while grading margin involvement and PALNS+ significantly influenced disease-free survival. In this experience, the number of involved lymph nodes ( $<3$ or $>3$ ) and the lymph node ratio did not impact survival outcome. Median overall and diseasefree survival time were significantly longer in patients with PALNs- compared to patients with PALNs+: $25 \mathrm{mo}$ vs $19 \mathrm{mo}, P=0.02$ (Figure $1 \mathrm{~A}$ ) and $12 \mathrm{mo}$ vs $8 \mathrm{mo}, P$
$=0.005$ (Figure 1B), respectively. When the patients analyzed for grading were stratified according to PALNs involvement, PALNs metastasis was related to survival only in G1-G2 differentiated cancers, both for overall $(P=0.02)$ (Figure $2 \mathrm{~A})$ and disease-free survival $(P=$ 0.004 ) (Figure 2B).

\section{Multivariate analysis}

Multivariate analysis showed that tumor differentiation 
Sperti C et al. Pancreatic cancer and para-aortic nodes

Table 4 Multivariate analysis for overall survival and disease-free survival in 151 patients resected for pancreatic adenocarcinoma

\begin{tabular}{|c|c|c|c|c|}
\hline & \multicolumn{2}{|c|}{ Overall survival } & \multicolumn{2}{|c|}{ Disease-free survival } \\
\hline & HR $(95 \% C I)$ & $P$ value & HR $(95 \% \mathrm{CI})$ & $P$ value \\
\hline Grading & $2.518(1.677-3.780)$ & 0.000 & $2.266(1.498-3.428)$ & 0.000 \\
\hline Stage & $1.137(0.676-1.915)$ & 0.628 & $0.960(0.570-1.615)$ & 0.877 \\
\hline PALNs status & $1.376(0.776-2.441)$ & 0.275 & $1.519(0.869-2.656)$ & 0.143 \\
\hline
\end{tabular}

PALNs: Para-aortic node status.

A

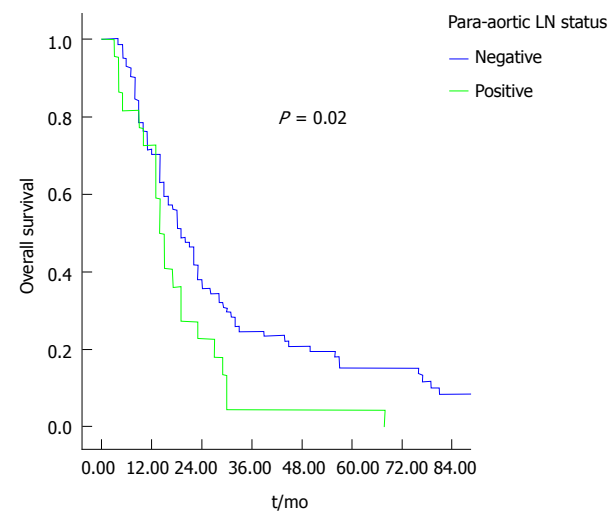

B

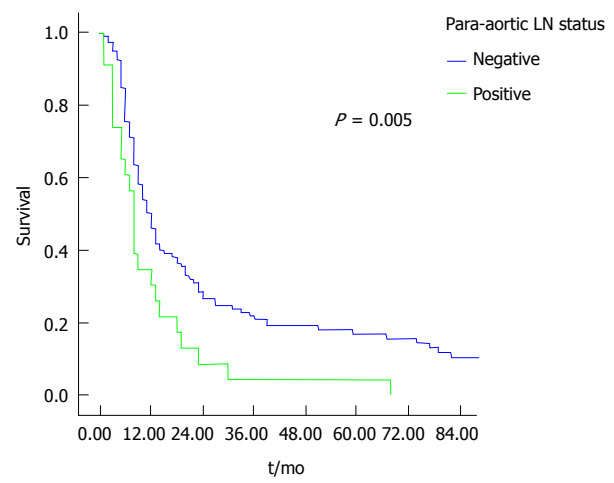

Figure 1 Comparison of overall survival (A) and disease-free survival (B) curves between patients with or without para-aortic nodes involvement. PALNs: Para-aortic lymph nodes.

was the only independent predictor of long-term survival (Table 4), while grading and margin involvement were independent prognostic factors for disease-free survival (Table 4). When lymph node status, lymph node ratio, and margin involvement were excluded from multivariate analysis, grading was confirmed to be the only independent predictor of disease-free and overall survival $(P<0.0001)$.

\section{Follow-up}

One hundred and seventeen patients with PALNsexperienced tumor's recurrence. Among them, 14 were long-term survivors (> 5-years) (11\%): 5 died for recurrent tumor and 9 are still alive without disease. Two patients with PALNs+ $(8 \%)$ survived more than five years after operation: one died for local and lung recurrences 65 mo after PD associated with venous
A

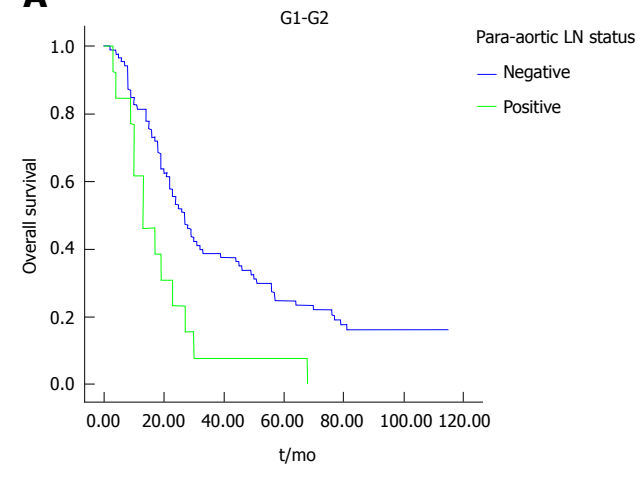

B

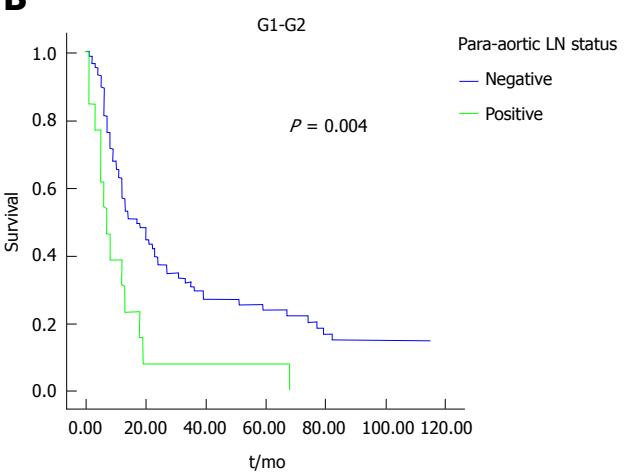

Figure 2 Comparison of overall survival (A) and disease-free survival (B) curves between patients with PALNs+ and PALNs- in the subgroup of G1-G2 grade cancer. PALNs: Para-aortic lymph nodes.

resection, and one is alive with lung metastases 70 mo after surgery.

\section{DISCUSSION}

In our experience of 151 patients with pancreatic adenocarcinoma who had undergone PD and paraaortic lymph node sampling, the involvement of PALNs has been shown in $16.5 \%$ of patients, in the range previously reported by other studies (10.4-29.4, mean $17.8 \%)^{[4]}$. PALNs metastasis was associated with more advanced disease (lymph node metastases and non-radical resection) and with poorer disease-free and overall survival. However, multivariate analysis of prognostic factors showed that only poor grade differentiation of the tumor and non-radical resection were associated with poor long-term outcome. Paraaortic node metastasis was not independent predictor of disease-free and overall survival, showing that paraaortic nodes involvement cannot be considered an 
absolute contraindication to pancreatic resection in pancreatic cancer patients. This is in contrast with the traditional thought that when positive para-aortic nodes have been detected, a systemic disease may occur, and surgical resection should be abandoned ${ }^{[13-16]}$. On the other hand, extended lymphadenectomy failed the target of prolonging long term survival after PD for pancreatic head cancer ${ }^{[17-20]}$.

There are increasing reports of long-term survival

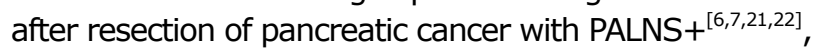
and, based on other prognostic parameters, more selective surgical indication has been suggested. Nappo et $a^{[23]}$ prospectively evaluated 135 patients undergoing PD and PALNs dissection, and found that survival of patients with PALNs+ seems to be comparable to that of patients with other lymph nodes involvement: the presence of PALNs+ should be not considered an absolute contraindication to radical surgery. Multivariate survival analysis of $\mathrm{N} 16+$ pancreatic cancer patients has been performed by several Authors in order to identify which patients with PALNs+ may benefit from resection. Tumor size ${ }^{[21,24]}$, tumor differentiation ${ }^{[24]}$, and absence of venous infiltration $^{[21]}$ have been identified as independent prognostic factors. Moreover, adjuvant chemotherapy has been shown to significantly improve the survival of patients with para-aortic lymph node metastasis ${ }^{[25-27]}$. Recently, Sho et $\left.a\right|^{[28]}$ reported a multicentric retrospective analysis of 822 patients who underwent pancreatic resection with pathological evaluation of PALNs for pancreatic ductal adenocarcinoma: metastatic PALNs were associated with poorer survival, but PALNs metastasis did not have a significant prognostic value at multivariate analysis. Some patients with metastatic PALNs may survive for longer than expected after pancreatectomy. There are two recent meta-analysis evaluating the prognostic impact of positive paraaortic nodes in pancreatic cancer patients. Paiella et $a^{[29]}$ collected 2141 patients ( $17 \%$ with PALNs+) from 13 eligible studies published in the Literature (most retrospective studies): PALNs metastasis was associated with poor prognosis, but the definitive avoidance of the resection when PALNs+ are detected intraoperatively, needs further investigations. More recently, Agalianos et $a I^{[8]}$, reviewed 10 retrospective and 2 prospective non randomized studies including 2467 patients. Although, involvement of PALNs was associated with decreased survival, the existence of long term survivors among the subgroup of patients with positive para-aortic nodes, requires further evaluation in order to identify factors conditioning more favorable outcome.

Limitations of our study include its retrospective design, the relative small number of patients with PALNs metastasis, and the change of medical treatment of recurrent tumor that eventually occurred in the study period.

Another critical point is the type of para-aortic nodes dissection to be performed, since it is not always reported or appears different in several reports. Japan
Pancreas Society ${ }^{[9]}$ distinguish four subgroups of paraaortic lymph nodes: stations 16a1, 16a2, 16b1 and $16 \mathrm{~b} 2$, from the aortic hiatus to the aortic bifurcation. We routinely dissect station $16 \mathrm{~b} 1$ because it is easy to perform after Kocher's maneuver and it does not increase the postoperative morbidity. Although some members of the International Study Group on Pancreatic Surgery resect $16 \mathrm{~b} 1$, because they include it in the resection plane, no strong recommendation could be formulated on dissecting $16 \mathrm{~b} 1$ routinely ${ }^{[30]}$. In the literature, there are not adequate data on the number of lymph nodes removed, and their metastasis rate within the subgroups $16 a 1,16 a 2,16 b 1$ and 16 b2. However, Kayahara et $a^{[6]}$ reported that all positive lymph nodes were located in the $16 \mathrm{M}$ region that corresponds to $16 \mathrm{a} 2$ and $16 \mathrm{~b} 1$ stations. Nappo et $a$ I $^{[23]}$ performed $16 \mathrm{a} 2$ and $16 \mathrm{~b} 1$ nodes dissection, and found $11.1 \%$ overall rate of para-aortic nodal metastases. Furthermore, Schwarz et al ${ }^{[16]}$ harvested a 5 -cm portion of the lymphocellular aortocaval tissue located below the left renal vein ( $16 \mathrm{~b} 1$ station). The mean \pm SD number of identified para-aortic nodes per patient was $4.5 \pm 1.1$ in the node-positive group and $2.9 \pm 1.3$ in the node negative group. So, complete $16 \mathrm{~b} 1$ dissection seems to be adequate for a better tumor staging and should be included in a standard lymphadenectomy ${ }^{[4]}$.

In conclusion, our study confirms that para-aortic node metastatic rate is relevant in pancreatic cancer patients. Survival is significantly decreased in patients with PALNs+, but PALNs involvement is not independent predictor of survival in these patients. Further large, prospective, multicentric studies are necessary to definitively determine the real role of PALNs involvement after resection for pancreatic adenocarcinoma. At the moment, it appears that the decision to perform pancreatic resection should not be taken on the basis of para-aortic lymph node status only.

\section{COMMENTS}

\section{Background}

Lymph nodes status is traditionally one of the most important prognostic factor for patients who underwent resection for pancreatic cancer. Para-aortic node involvement (PALNs) by pancreatic cancer is generally considered as metastatic disease, and resection is not recommended. However, some Author reported survival benefit after surgery even when para-aortic nodes were involved by the tumors; so, the real impact of PALNs involvement in pancreatic cancer patients is still controversial.

\section{Research frontiers}

Aim of this study was to evaluate early and late outcome of pancreatic cancer patients who underwent pancreatectomy with sampling of para-aortic nodes. The authors retrospectively examined our experience of 151 patients with pancreatic cancer who underwent resection and para-aortic lymph nodes sampling. Data were obtained from a retrospective analysis of a prospective data base of patients who underwent pancreaticoduodenectomy or total pancreatectomy with para-aortic node (PALNs) sampling between January 2000 to December 2012 in the authors' Department. They were divided into two groups: patients with negative PALNs (PALNs-), and patients with metastatic PALNs (PALNs+). The two groups were compared in term of demographic features, comorbidities, surgical procedures, perioperative findings, tumor pathological characteristics, 
perioperative outcomes, disease-free and overall survival.

\section{Innovations and breakthroughs}

In this experience, disease-free and overall survival were worse in patients with para-aortic nodes metastases, but multivariate analysis showed that paraaortic node involvement is not an independent prognostic factor after resection of pancreatic cancer. In fact, multivariate analysis of prognostic factors showed that only poor grade differentiation of the tumor and non-radical resection were associated with poor long-term outcome. Para-aortic node metastasis was not independent predictor of disease-free and overall survival, showing that paraaortic nodes involvement cannot be considered an absolute contraindication to pancreatic resection in pancreatic cancer patients. This is in contrast with the traditional thought that when positive para-aortic nodes have been detected, a systemic disease may occur, and surgical resection should be abandoned. So, the decision to make pancreatic resection should not be based on the paraaortic node status only.

\section{Applications}

This study confirms that para-aortic node metastatic rate is relevant in pancreatic cancer patients. Survival is significantly decreased in patients with PALNs+, but PALNs involvement is not independent predictor of survival in these patients. Further large, prospective, multicentric studies are necessary to definitively determine the real role of PALNs involvement after resection for pancreatic adenocarcinoma. At the moment, it appear that the decision to perform pancreatic resection should not be taken on the basis of para-aortic lymph node status only.

\section{Terminology}

In this study we have evaluated the presence of PALNs in patients operated on for pancreatic head adenocarcinoma. Patients were divided in two groups: patients with negative PALNs (PALNs-), and patients with metastatic PALNs (PALNs+).

\section{Peer-review}

This is a good study worthy of publication and reports 151 patients undergoing pancreaticoduodenectomy for pancreatic adenocarcinoma. The histological data on resection margins, lymph node status, etc. is reproducible across other data sets. The authors have chosen to concentrate on the presence or absence of $L N$ metastases in the para-aortic lymph node groups. In doing so they have inevitably ended with very small sub-set analysis from which it is difficult to make firm conclusions.

\section{REFERENCES}

1 Siegel RL, Miller KD, Jemal A. Cancer statistics, 2015. CA Cancer J Clin 2015; 65: 5-29 [PMID: 25559415 DOI: 10.3322/caac.21254]

2 Strobel O, Hinz U, Gluth A, Hank T, Hackert T, Bergmann F, Werner J, Büchler MW. Pancreatic adenocarcinoma: number of positive nodes allows to distinguish several N categories. Ann Surg 2015; 261: 961-969 [PMID: 24979603 DOI: 10.1097/SLA.0000 000000000814]

3 Orci LA, Meyer J, Combescure C, Bühler L, Berney T, Morel $\mathrm{P}$, Toso C. A meta-analysis of extended versus standard lymphadenectomy in patients undergoing pancreatoduodenectomy for pancreatic adenocarcinoma. $H P B$ (Oxford) 2015; 17: 565-572 [PMID: 25913578 DOI: 10.1111/hpb.12407]

4 Pedrazzoli S. Extent of lymphadenectomy to associate with pancreaticoduodenectomy in patients with pancreatic head cancer for better tumor staging. Cancer Treat Rev 2015; 41: 577-587 [PMID: 26045226 DOI: 10.1016/j.ctrv.2015.04.013]

5 Slidell MB, Chang DC, Cameron JL, Wolfgang C, Herman JM, Schulick RD, Choti MA, Pawlik TM. Impact of total lymph node count and lymph node ratio on staging and survival after pancreatectomy for pancreatic adenocarcinoma: a large, populationbased analysis. Ann Surg Oncol 2008; 15: 165-174 [PMID: 17896141 DOI: $10.1245 /$ s10434-007-9587-1]

6 Kayahara M, Nagakawa T, Ohta T, Kitagawa H, Ueno K, Tajima H, Elnemr A, Miwa K. Analysis of paraaortic lymph node involvement in pancreatic carcinoma: a significant indication for surgery? Cancer 1999; 85: 583-590 [PMID: 10091731]

7 Sakai M, Nakao A, Kaneko T, Takeda S, Inoue S, Kodera Y, Nomoto S, Kanazumi N, Sugimoto H. Para-aortic lymph node metastasis in carcinoma of the head of the pancreas. Surgery 2005; 137: 606-611 [PMID: 15933626 DOI: 10.1016/j.surg.2005.02.009]

8 Agalianos C, Gouvas N, Papaparaskeva K, Dervenis C. Positive para-aortic lymph nodes following pancreatectomy for pancreatic cancer. Systematic review and meta-analysis of impact on short term survival and association with clinicopathologic features. $H P B$ (Oxford) 2016; 18: 633-641 [PMID: 27485057 DOI: 10.1016/ j.hpb.2016.04.007]

9 Japan Pancreas Society. Classification of pancreatic carcinoma (2nd English edition), Japan Pancreas Society editor, Tokyo, Kanehara \& Co., 2003

10 Menon KV, Gomez D, Smith AM, Anthoney A, Verbeke CS. Impact of margin status on survival following pancreatoduodenectomy for cancer: the Leeds Pathology Protocol (LEEPP). $H P B$ (Oxford) 2009; 11: 18-24 [PMID: 19590619 DOI: 10.1111/ j.1477-2574.2008.00013.x]

11 Sobin LH, Wittekind C, Gospodarowicz M. Union for International Cancer Control: TNM classification of malignant tumors. 7th edition. New York: Wiley-Liss, 2009

12 Bassi C, Dervenis C, Butturini G, Fingerhut A, Yeo C, Izbicki J, Neoptolemos J, Sarr M, Traverso W, Buchler M. Postoperative pancreatic fistula: an international study group (ISGPF) definition. Surgery 2005; 138: 8-13 [PMID: 16003309 DOI: 10.1016/ j.surg.2005.05.001]

13 Yoshida T, Matsumoto T, Sasaki A, Shibata K, Aramaki M, Kitano S. Outcome of paraaortic node-positive pancreatic head and bile duct adenocarcinoma. Am J Surg 2004; 187: 736-740 [PMID: 15191867 DOI: 10.1016/j.amjsurg.2003.07.031]

14 Shimada K, Sakamoto Y, Sano T, Kosuge T. The role of paraaortic lymph node involvement on early recurrence and survival after macroscopic curative resection with extended lymphadenectomy for pancreatic carcinoma. J Am Coll Surg 2006; 203: 345-352 [PMID: 16931307 DOI: 10.1016/j.jamcollsurg.2006.05.289]

15 Doi R, Kami K, Ito D, Fujimoto K, Kawaguchi Y, Wada M, Kogire M, Hosotani R, Imamura M, Uemoto S. Prognostic implication of para-aortic lymph node metastasis in resectable pancreatic cancer. World J Surg 2007; 31: 147-154 [PMID: 17171496 DOI: 10.1007/ s00268-005-0730-5]

16 Schwarz L, Lupinacci RM, Svrcek M, Lesurtel M, Bubenheim M, Vuarnesson H, Balladur P, Paye F. Para-aortic lymph node sampling in pancreatic head adenocarcinoma. Br J Surg 2014; 101: 530-538 [PMID: 24633831 DOI: 10.1002/bjs.9444]

17 Nimura Y, Nagino M, Takao S, Takada T, Miyazaki K, Kawarada Y, Miyagawa S, Yamaguchi A, Ishiyama S, Takeda Y, Sakoda K, Kinoshita T, Yasui K, Shimada H, Katoh H. Standard versus extended lymphadenectomy in radical pancreatoduodenectomy for ductal adenocarcinoma of the head of the pancreas: long-term results of a Japanese multicenter randomized controlled trial. $J$ Hepatobiliary Pancreat Sci 2012; 19: 230-241 [PMID: 22038501 DOI: 10.1007/s00534-011-0466-6]

18 Jang JY, Kang MJ, Heo JS, Choi SH, Choi DW, Park SJ, Han SS, Yoon DS, Yu HC, Kang KJ, Kim SG, Kim SW. A prospective randomized controlled study comparing outcomes of standard resection and extended resection, including dissection of the nerve plexus and various lymph nodes, in patients with pancreatic head cancer. Ann Surg 2014; 259: 656-664 [PMID: 24368638 DOI: 10.1097/SLA.0000000000000384]

19 Iqbal N, Lovegrove RE, Tilney HS, Abraham AT, Bhattacharya S, Tekkis PP, Kocher HM. A comparison of pancreaticoduodenectomy with extended pancreaticoduodenectomy: a meta-analysis of 1909 patients. Eur J Surg Oncol 2009; 35: 79-86 [PMID: 18356005 DOI: 10.1016/j.ejso.2008.01.002]

20 Xu X, Zhang H, Zhou P, Chen L. Meta-analysis of the efficacy of pancreatoduodenectomy with extended lymphadenectomy in the treatment of pancreatic cancer. World J Surg Oncol 2013; 11: 311 [PMID: 24321394 DOI: 10.1186/1477-7819-11-311]

21 Yamada S, Fujii T, Sugimoto H, Kanazumi N, Kasuya H, 
Nomoto S, Takeda S, Kodera Y, Nakao A. Pancreatic cancer with distant metastases: a contraindication for radical surgery? Hepatogastroenterology 2009; 56: 881-885 [PMID: 19621722]

22 Hafeez Bhatti AB, Dar FS, Sahaab E, Khan NY, Zia H, Rana A, Salih M, Shah NH. Survival advantage with para aortic lymphadenectomy in peri-ampullary cancer: A retrospective cohort study. Int J Surg 2016; 31: 58-62 [PMID: 27262530 DOI: 10.1016/j.ijsu. 2016.05.069]

23 Nappo G, Borzomati D, Perrone G, Valeri S, Amato M, Petitti $\mathrm{T}$, Coppola R. Incidence and prognostic impact of para-aortic lymph nodes metastases during pancreaticoduodenectomy for periampullary cancer. $H P B$ (Oxford) 2015; 17: 1001-1008 [PMID: 26335256 DOI: 10.1111/hpb.12497]

24 Liu C, Lu Y, Luo G, Cheng H, Guo M, Liu Z, Xu J, Long J, Liu L, Fu D, Ni Q, Li M, Yu X. Which patients with para-aortic lymph node (LN16) metastasis will truly benefit from curative pancreaticoduodenectomy for pancreatic head cancer? Oncotarget 2016; 7: 29177-29186 [PMID: 27081079 DOI: 10.18632/oncotarget.8690]

25 Murakami Y, Uemura K, Sudo T, Hashimoto Y, Yuasa Y, Sueda T. Prognostic impact of para-aortic lymph node metastasis in pancreatic ductal adenocarcinoma. World J Surg 2010; 34: 1900-1907 [PMID: 20376442 DOI: 10.1007/s00268-010-0577-2]

26 Lin JY, Zhang XM, Kou JT, Fa H, Zhang XX, Dai Y, He Q. Analysis of prognostic factors for pancreatic head cancer according to para-aortic lymph node. Cancer Med 2016; 5: 2701-2707 [PMID: 27541833 DOI: 10.1002/cam4.853]
27 Komo T, Murakami Y, Kondo N, Uemura K, Hashimoto Y, Nakagawa N, Urabe K, Takahashi S, Sueda T. Prognostic Impact of Para-Aortic Lymph Node Micrometastasis in Pancreatic Ductal Adenocarcinoma. Ann Surg Oncol 2016; 23: 2019-2027 [PMID: 26856722 DOI: 10.1245/s10434-016-5120-8]

28 Sho M, Murakami Y, Motoi F, Satoi S, Matsumoto I, Kawai M, Honda G, Uemura K, Yanagimoto H, Kurata M, Fukumoto T, Akahori T, Kinoshita S, Nagai M, Nishiwada S, Unno M, Yamaue $\mathrm{H}$, Nakajima Y. Postoperative prognosis of pancreatic cancer with para-aortic lymph node metastasis: a multicenter study on 822 patients. J Gastroenterol 2015; 50: 694-702 [PMID: 25341657 DOI: 10.1007/s00535-014-1005-4]

29 Paiella S, Sandini M, Gianotti L, Butturini G, Salvia R, Bassi C. The prognostic impact of para-aortic lymph node metastasis in pancreatic cancer: A systematic review and meta-analysis. Eur $J$ Surg Oncol 2016; 42: 616-624 [PMID: 26916137 DOI: 10.1016/ j.ejso.2016.02.003]

30 Tol JA, Gouma DJ, Bassi C, Dervenis C, Montorsi M, Adham M, Andrén-Sandberg A, Asbun HJ, Bockhorn M, Büchler MW, Conlon KC, Fernández-Cruz L, Fingerhut A, Friess H, Hartwig W, Izbicki JR, Lillemoe KD, Milicevic MN, Neoptolemos JP, Shrikhande SV, Vollmer CM, Yeo CJ, Charnley RM. Definition of a standard lymphadenectomy in surgery for pancreatic ductal adenocarcinoma: a consensus statement by the International Study Group on Pancreatic Surgery (ISGPS). Surgery 2014; 156: 591-600 [PMID: 25061003 DOI: 10.1016/j.surg.2014.06.016]

P- Reviewer: Aosasa S, Bramhall S, Izbicki JR, Kleeff J, Ramia JM, Tamoto E, Welsch TS

S- Editor: Gong ZM L- Editor: A E- Editor: Li D 